Available online at GSC Online Press Directory

GSC Biological and Pharmaceutical Sciences

e-ISSN: 2581-3250, CODEN (USA): GBPSC2

Journal homepage: https://www.gsconlinepress.com/journals/gscbps

(REVIEW ARTICLE)

\title{
Role of exercise and physical activity in prevention and management of chronic diseases
}

\author{
Bello Samuel *, Adeniji Adedamola, Akeredolu Oladayo and Idowu Temitope \\ Department of Biochemistry, Faculty of Basic Medical Sciences, College of Medicine, University of Ibadan, Ibadan, Nigeria.
}

Publication history: Received on 26 August 2020; revised on 09 September 2020; accepted on 12 September 2020

Article DOI: https://doi.org/10.30574/gscbps.2020.12.3.0277

\begin{abstract}
The burden of chronic disease and the cost of treatment and management has skyrocketed. According to the World Health Organization (WHO), an estimated 17.9 million people died from cardiovascular diseases (CVDs) in 2016 making it the leading cause of death. Cancer is the second leading cause of death globally and was responsible for an estimated 9.6 million deaths in 2018, there are other chronic diseases which include obesity, diabetes, chronic obstructive pulmonary diseases (COPD), dementia and Alzheimer's disease. Most chronic diseases can be caused and aggravated by physical inactivity amongst other factors. However, physical activity and exercise when properly implemented demonstrate tremendous effect in the prevention and management of several chronic diseases and health related conditions. This review focuses on the role of exercise in prevention and management of chronic diseases and the biochemical mechanism underlying it.
\end{abstract}

Keywords: Chronic disease; Physical activity; Exercise; Prevention; Management; Treatment

\section{Introduction}

Chronic diseases are diseases that are not infectious, slowly progressing, prolonged and usually caused by genetics, environmental factors and poor lifestyle [1]. In recent years there has been an astronomical rise in the incidence of chronic diseases due to the adoption of sedentary lifestyle (physical inactivity) coupled with excessive caloric intake. Epidemiological, experimental and clinical evidence abounds to prove that behavioural risk factors such as sedentary lifestyle, unhealthy diets, tobacco and alcohol initiates dysfunctions that cause chronic diseases [2,3,4]. Physical inactivity is a modifiable risk factor that increases the risk of developing chronic diseases [5]. Hence physical activity and exercise will both help to ameliorate and prevent chronic disease conditions.

\section{Exercise and Physical Activity}

Exercise and physical activity though often used interchangeably, have somewhat different definitions. According to Zanuso et al (2010): Physical activity involves movement of the parts of the body produced by the contraction of skeletal muscle that expend energy higher than the resting energy [6]. It can include activities related to work, leisure or daily routine. On the other hand, exercise is a subset of physical activity that is organised and executed in order to improve or sustain physical fitness [7].

Exercise is categorized based on the type, ferocity and time span of activity. Exercise can be classified into three: Aerobic, anaerobic and flexibility exercise. Aerobic or endurance exercise is an exercise that causes the body to use more oxygen thus improving cardiovascular endurance, examples include running, swimming, brisk walking, skipping rope, dancing

\footnotetext{
* Corresponding author: Bello Samuel; +234-8136361457 bell21119@gmail.com

Department of Biochemistry, Faculty of Basic Medical Sciences, College of Medicine, University of Ibadan, Ibadan, Nigeria.
} 
etc ${ }^{8}$. Anaerobic, strength or resistance training can increase body mass and improve bone density and balance, examples include push-ups, pull-ups, squats, weightlifting and sprinting. Flexibility exercises involves stretching of muscles to improve flexibility and movements around the joints [8].

Endurance exercise involves protracted periods of muscle contraction activity against low resistance, while resistance exercise involves brief periods of muscle contraction activity against a high resistance. Conversely, sprint exercise occurs during short periods of intense and recurrent muscle contraction activity against a low resistance, such as running a 100m sprint race [9]. Regular exercise prevents condition like diabetes, cardiovascular diseases and obesity, though humans exhibit varying degree of responses to exercises due to genetic differences [10]. Junk diet and physical inactivity causes more than 300,000 deaths per year [10] and physical inactivity is an independent risk factor for cardiovascular diseases $[11,12]$.

Researchers have proven that there is a prevalence of chronic metabolic diseases like diabetes, obesity, and coronary heart diseases among individuals with low intrinsic exercise capacity $[13,14,15]$, thus linking aerobic capacity to several chronic diseases. Endurance exercise like running, cycling, swimming, and other aerobic exercises can be referred to as cardiovascular exercise [16]. Endurance exercise educes both muscular and systemic responses as a result of its physiological and biochemical requirements [10]. Endurance exercise has been proven to cause major adaptations like: change in the mechanical, metabolic and contractile role in muscle; reduced glycogen reserve [17]; equilibrated electrolytes [18] and enhanced mitochondrial biogenesis [19].

\section{Exercise and Physical Activity in Prevention and Management of Chronic Diseases}

Studies have shown the efficacy of physical activities and a lifestyle of continuous exercise. It has been observed that physical activities play a beneficial role in the health of both the young and the old [20]. Lack of physical activity and poor dietary routine is associated to development of conditions such as obesity [21] and progressiveness of several lifethreatening chronic diseases such as cancer, cardiovascular diseases, neurological diseases, metabolic diseases and immune related disorders [22]. It has also been shown that regular physical activity is associated with improve cellular functions and tissue processes resulting in a healthier biological system [1]. The inclusion of physical activities to prevent sicknesses showed a highly significant decreased susceptibility to type 2 diabetes [23], an 80\% decreased vulnerability to CVD [24], and a 33\% decreased susceptibility to cancer [25], and sometimes there is a decrease in risk of early death due to chronic illness [26], aging or both.

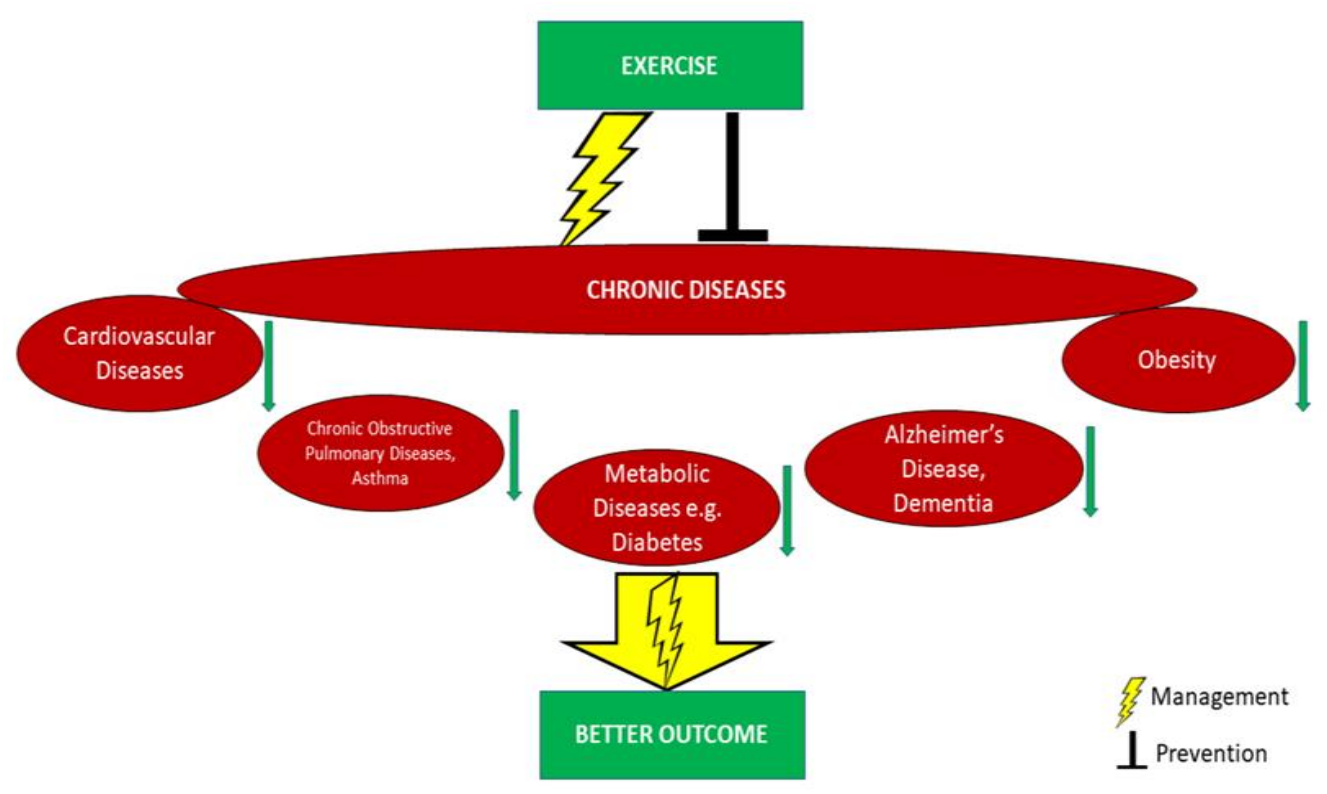

Figure 1 Dual effect of exercise in prevention and management of chronic diseases

Most scientific research has shown that exercise impacts positively on the human body system and it would be safe to say exercise may serve as a form of treatment and management for different disease conditions. This literature focuses on some prevalent chronic disease conditions and how exercise prevents, improves and modulates the condition. Recently, Doctors have started seeing the efficacy of targeted exercise in many medical conditions. Diabetes and obesity 
experts have now emphasized regular exercise as a confirmed therapy [27], while geriatricians have included exercise in the regime of older patients to improve their well-being [28]. Some common diseases and the effect of exercise in their prevention and management are highlighted as follows.

\subsection{Obesity}

A study by Laskowsi (2018) revealed that high intensity interval training is an effectual and therapeutic exercise relevant for combating obesity [29]. Another review showed that lack of physical activities and exercise increased the risk of morbidity in inactive obese patients [30]. Booth et al (2017) showed that lack of physical activities increased the weight of rats within just 2-7 days and revealed that inactivity increases risk of obesity and causes reduced insulin sensitivity [22]. Research has shown a relationship between the intensity and amount of exercise and the level of weight loss in total body fat and visceral adipose tissue. Friedenreich et al (2010) concluded from their research on postmenopausal women that a minimum dose of exercise is needed to reduce body fat with greater result observed with individuals engaging in a higher volume of training [31].

\subsection{Diabetes}

Aune et al (2015) showed that inactivity groups showed over $26 \%$ increased susceptibility to type 2 diabetes than in high activity groups in meta-analyses when total activity was determined in 14 cohort studies and inactivity was reported in a different 55 cohort studies, respectively [32]. Hu et al (2004) made findings showing that although obesity is a risk factor for type 2 diabetes, increased physical activity reduced the risk [33]. Obese individuals with high levels of physical activities had less than half the relative risk of type 2 diabetes compared to obese individuals who had low levels of physical activities [33]. In addition, Meta-analysis by Kelly and Kelly demonstrated that exercise decreased the amount of body fat in obese and overweight children and teenagers [34], thereby decreasing their chances of developing diabetes.

\subsection{Cancer}

According to WHO, around 31\% of adults worldwide are physically inactive [35]. The panel concluded that regular, sustained physical activities protects against several types of cancer independent of body fat [36]. Physical activities have been shown to cause a $20 \%$ decreased susceptibility to colon cancer [37]. A cohort of more than 40,000 men in the USA showed that aerobic exercise and physical activities seems to be more effective and that all-round physical activity is more effective than the intensity of the exercise [38]. Most studies show a protective effect with a $13 \%$ decreased risk in high versus low physical activity groups [39].

Cancer risk is associated with body weight and inactivity, and the prevention of adiposity may be the link between physical activity and cancer. A $20 \%$ decrease in susceptibility to cancer in high versus low physical activity groups was shown using a meta-analysis [40]. This inverse association was only observed in overweight/obese women [40]. A 27\% decrease in lung cancer incidence in the high versus low physical activity group was also seen among smokers [41]. It is crucial to understand the efficacy of exercise as a safe and effective therapy in patients fighting cancer. However, the precaution varies for different prognosis of the disease, and exercise routines should be under supervision of a specialist.

\subsection{Cardiovascular Diseases}

Exercise has the ability to decrease susceptibility to cardiovascular diseases (CVD) such as coronary artery disease, atherosclerosis and more via several methods [42]. Some of the different mechanisms on the heart includes improved myocardial contraction, electrical stability, increased dilation capacity of coronary arteries, decreased rate of coronary artery atherosclerosis. In addition, high levels of activity are associated with low blood pressure, high levels of highdensity lipoproteins and lower levels of low-density lipoproteins and increased insulin sensitivity and glucose tolerance [43]. It was observed that individuals who were moderately inactive had a substantially lower CVD risk than those who were completely inactive, suggesting that even modest engagement in physical activity may be associated with a substantially lower risk of CVD [44].

\subsection{Chronic Respiratory Diseases}

Chronic obstructive pulmonary disease (COPD) and asthma (most prevalent chronic respiratory disorder), constitute health burden for health workers, inhaled therapeutics has been the main treatment for asthma [45] and COPD however exercise can improve health conditions of patients [46]. Exercise triggers off asthmatic symptoms like wheezing and/or shortness of breath in most asthmatics and this is because during vigorous physical activities there is loss of heat and water causing the lungs to be dry and leading to constriction of the bronchi [47]. Hence, asthmatics may need to take 
their medications (mostly aerosols) before exercise to prevent asthmatic symptoms due to exercise. Walking and other aerobic exercises are recommended for asthmatic individuals, although other vigorous exercises such as basketball and running are not encouraged as they have higher probability of causing symptoms [48].

There is no confirmation of a general degree of exercise required however, the level that is tolerated without any symptom is recommended. Patients that are just starting may need to start from a minimum level and then increase the exercise as much as their condition permits [49]. Exercise and physical activities are usually for up to 30 minutes at a stretch and it is advisable that the patient rests before the next one. Daily physical activity like walking has protective effects and walking in patients with asthma can improve quality of life and control asthma [48].

Physical activities and exercise should be encouraged at the early diagnosis of COPD and being able to maintain a level of physical activity (as their condition can permit without symptom) in individuals with COPD such as bronchitis and emphysema, is associated with a better prognosis in their conditions [50].

\subsection{Cognitive Function and Mental Health}

Benefits of exercise and physical activity also includes: increase in cerebral blood flow and maximal oxygen consumption, delivery of oxygen to cerebral tissue, reduction in muscle tension and increased serum concentrations of endocannabinoid receptors [51]. Physical activities and exercise have been found to increase the levels of neurotransmitters like serotonin and endorphins [52]. Studies have consistently proven the benefits of exercise and physical activities in reducing depression [53]. It has also been seen that people that practice exercise frequently are not often depressed and do not suffer anxiety [54]. Therefore, physical activity can act as a cheap therapy for these conditions.

Exercise and constant physical activities have also been shown to foster the release of peripheral Brain Derived Neurotrophic Factor (BDNF) [55], improve cerebrovascular health, increase blood flow, and facilitates easier transport of nutrient and energy to the brain [56]. Several studies revealed that exercise enhances cognitive functions in adolescents and aged adults [57,58]. Physical activities also prevent cognitive deterioration associated with aging [59]. Exercise and frequent physical activity also decrease the risk of having dementia [56], prevents deterioration of other mental abilities [60] and it also enhances the quality of life [61].

\section{Protective Mechanism of Exercise}

The therapeutic role of exercise is due to the various protective biochemical mechanisms underlying it, these mechanisms include activation of insulin-like growth factor (IGF-1), brain derived neurotrophic factor (BDNF) and two major pathways: Peroxisome proliferator-activated receptor- $\gamma$ coactivator $1 \alpha$ (PGC-1 $\alpha$ ) and Nuclear factor erythroid 2-related factor 2 (Nrf2) signaling pathways [62]. PGC-1 $\alpha$ and Nrf2 pathways both lead to the activation of nuclear respiratory factor 1 (NRF1) and subsequent transcription of genes involved in mitochondrial biogenesis [62].

PGC- $1 \alpha$ is a member of a family of transcription coactivators that plays a central role in the regulation of cellular energy metabolism, PGC- $1 \alpha$ is linked to alleviation of disorders such as obesity, diabetes, and heart diseases [63]. PGC-1 $\alpha$ activates mitochondrial biogenesis which is required for the continuous generation of mitochondria and mitochondria DNA which plays a major role in disease prevention and act as an anti-aging therapy [62]. PGC-1 $\alpha$ also activates fatty acid oxidation [64] and increased fatty acid oxidation improves insulin sensitivity [65]. PGC-1 $\alpha$ modulates signaling pathways such as $\mathrm{Ca}^{2+}$ /calmodulin-dependent signaling, AMPK signaling, p38 MAPK signaling, reactive nitrogen and oxygen species-dependent signaling in exerting therapeutic effects due to exercise [66].

Nrf2 is the master regulator of the antioxidant defense system, it is a transcription factor that regulates the expression of many cytoprotective genes. Studies reveal that Nrf2 signaling plays a major role in how oxidative stress due to exercise can trigger mitochondrial biogenesis and nitric oxide (NO) and hydrogen peroxide $\left(\mathrm{H}_{2} \mathrm{O}_{2}\right)$ released during exercise can activate antioxidant defenses such as heme oxygenase 1 (HO-1), NAD(P)H quinone dehydrogenase 1 (NQ01) and superoxide dismutase (SOD) by inhibiting Keap1 (cytosolic repressor of NrF2) from binding to form NrF2Keap1 complex, thus allowing NrF2 to bind and subsequently activate antioxidant response elements (AREs) in the nucleus [67]. 


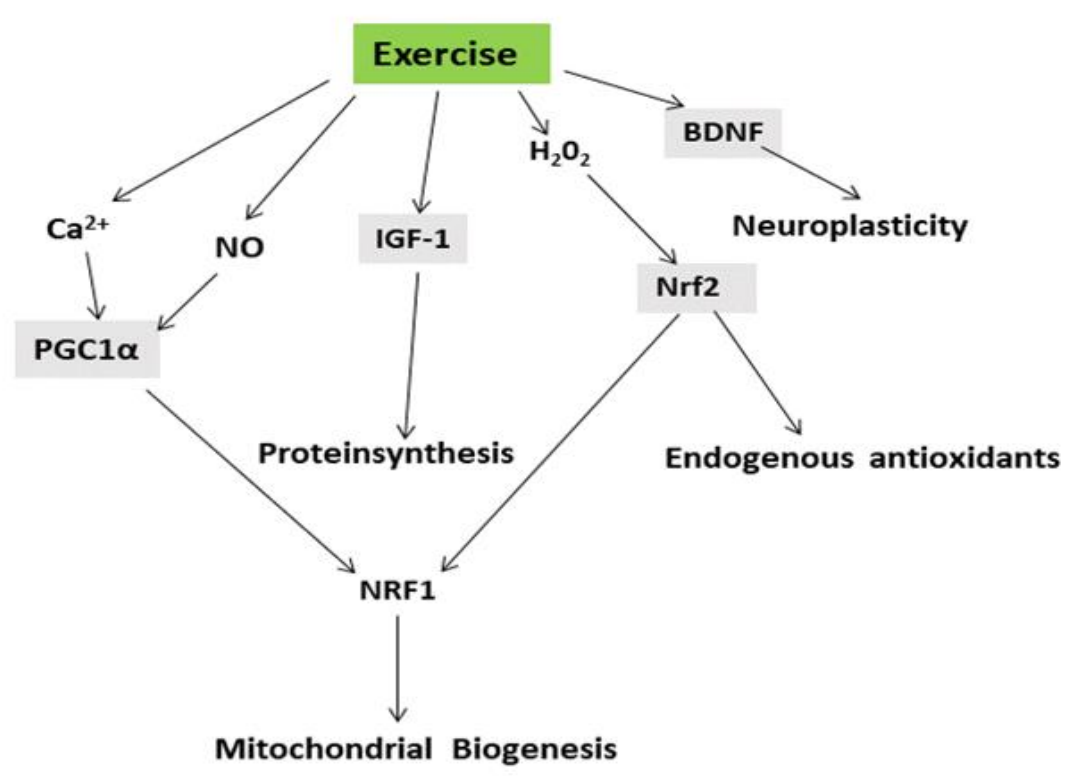

Figure 2 Protective Mechanism of Exercise

Research also shows a link between exercise, IGF-1, and BDNF. BDNF promotes neuroplasticity and neurogenesis, thereby improving cognitive function, mood and neuroprotection [68]. Physical exercise can upregulate growth factor signaling by decreasing proinflammatory signaling [69]. Exercise also induces noradrenalin and serotonin [70] which affect and improves mood. IGF-1, known for its role in child growth and increased body mass shows increased expression as a result of exercise, IGF-1 and vascular endothelial growth factor (VEGF) have also been shown to upregulate BDNF $[69,71]$ thereby improving brain health.

\section{Conclusion}

Physical inactivity is the primary cause of many chronic diseases. Exercise and Physical activity have been shown to have dual functions: effective in the treatment of chronic diseases, and more importantly help in the primary prevention of chronic diseases. The inclusion of exercise and physical activities in one's daily routine will reduce the risk of chronic diseases and its associated mortality. Thus, exercise and physical activity provides a healthy and cost-effective alternative to other treatment methods for chronic diseases especially because both are involved in primary disease prevention.

\section{Compliance with ethical standards}

\section{Acknowledgments}

The authors appreciate the support and contribution of Superminds Research Team.

\section{Disclosure of conflict of interest}

The authors declare no conflict of interest.

\section{References}

[1] Anderson E, Durstine JL. Physical Activity, Exercise, and Chronic Diseases: A Brief Review, Sports Medicine and Health Science.

[2] Booth FW, Laye MJ, Lees SJ, Rector RS, Thyfault JP. Reduced physical activity and risk of chronic disease: the biology behind the consequences. Eur J Appl Physiol. 2008; 102: 381-390.

[3] Booth FW, Lees SJ. Fundamental questions about genes, inactivity and chronic diseases. Physiol Genomics. 2007; 28: 146-157. 
[4] Olsen RH, Krogh-Madsen R, Thomsen C, Booth FW, Pedersen BK. Metabolic responses to reduced daily steps in healthy nonexercising men. JAMA. 2008; 19: 1261-1263.

[5] Katzmarzyk PT, Lear SA. Physical activity for obese individuals: a systematic review of effects on chronic disease risk factors. Obes Rev. 2012; 13(2): 95-105.

[6] Zanuso S, Jimenez A, Pugliese G, Corigliano G, Balducci S. Exercise for the management of type 2 diabetes: a review of the evidence, Acta Diabetologica. 2010; 47(1): 15-22.

[7] S Zanuso, S Balducci, A Jimenez. Physical activity, a key factor to quality of life in type 2 diabetic patients, Diabetes/Metabolism Research and Reviews. 2009; 25(1): S24-S28.

[8] National Institutes of Health, National Heart, Lung, and Blood Institute. Your Guide to Physical Activity and Your Heart". U.S. Department of Health and Human Services. 2006.

[9] Saeid G, Badran M, Laher I. Antioxidant and Anti-Inflammatory Effects of Exercise in Diabetic Patients. Experimental Diabetes Research. 2012; 941868.

[10] Tung Y-T, Hsu Y-J, Liao C-C, Ho S-T, Huang C-C, Huang W-C. Physiological and Biochemical Effects of Intrinsically High and Low Exercise Capacities Through Multiomics Approaches. Front. Physiol. 2019; 10: 1201.

[11] Blair SN, Kohl HW, Paffenbarger RS Jr, Clark DG, Cooper KH, Gibbons LW. Physical fitness and all-cause mortality: a prospective study of healthy men and women. JAMA. 1989; 262: 2395-2401.

[12] McGinnis JM, Foege WH. Actual causes of death in the United States. JAMA. 1993; 270: 2207-2212.

[13] Schwarzer M, Britton SL, Koch LG, Wisloff U, Doenst T. Low intrinsic aerobic exercise capacity and systemic insulin resistance are not associated with changes in myocardial substrate oxidation or insulin sensitivity. Basic. Res. Cardiol. 2010; 105: 357-364.

[14] Pekkala S, Lensu S, Nokia M, Vanhatalo S, Koch LG, Britton SL, et al. Intrinsic aerobic capacity governs the associations between gut microbiota composition and fat metabolism age-dependently in rat siblings. Physiol. Genom. 2017; 49: 733-746.

[15] Koch LG, Britton SL. Theoretical and biological evaluation of the link between low exercise capacity and disease risk. Cold Spring Harb. Perspect. Med. 2018; 8: a029868.

[16] Joyner MJ, Coyle EF. Endurance exercise performance: the physiology of champions. J. Physiol. 2008; 586, 35-44.

[17] Munoz A, Riber C, Trigo P, Castejon-Riber C, Castejon FM. Dehydration, electrolyte imbalances and reninangiotensinaldosteronevasopressin axis in successful and unsuccessful endurance horses. Equine. Vet. J. 2010; 42: 83-90.

[18] Russell AP, Lamon S, Boon H, Wada S, Güller I, Brown EL, et al. (2013). Regulation of miRNAs in human skeletal muscle following acute endurance exercise and short-term endurance training. J. Physiol. 2013; 591: 4637-4653.

[19] Snow DH, Baxter P, Rose RJ. Muscle fibre composition and glycogen depletion in horses competing in anendurance ride. Vet. Rec. 1981; 108: 374-378.

[20] Turner JE, Lira VA, Brum PC. New insights into the benefits of physical activity and exercise for aging and chronic disease. Oxidative Med Cell Longev. 2017.

[21] Aoike DT, Baria F, Kamimura MA, Ammirati A, Cuppari L. Home-based versus center-based aerobic exercise on cardiopulmonary performance, physical function, quality of life and quality of sleep of overweight patients with chronic kidney disease. Clin Exp Nephrol. 2018; 22(1): 88-96.

[22] Booth FW, Roberts CK, Thyfault JP, Ruegsegger GN, Toedebusch RG. Role of Inactivity in Chronic Diseases: Evolutionary Insight and Pathophysiological Mechanisms. Physiol Rev. 2017; 97: 1350-1400.

[23] Hamman RF, Wing RR, Edelstein SL, et al. Effect of weight loss with lifestyle intervention on risk of diabetes. Diabetes Care. 2006; 29(9): 2102-2107.

[24] Ades P, Balady G, Berra K. Transforming Exercise-based Cardiac Rehabilitation Programs into Secondary Prevention Centers: A National Imperative. J Cardiopulm Rehabil Prev. 2001; 21(5): 264-271.

[25] Warburton DE, Nicol CW, Bredin SS. Health benefits of physical activity: the evidence. CMAJ. 2006; 174(6): 801809.

[26] Fogelholm M. Physical activity, fitness and fatness: relations to mortality, morbidity and disease risk factors. A systematic review. Obes Rev. 2010; 11(3): 204-220. 
[27] Brownell KD. The LEARN program for weight management 2000. Dallas: American Health Publishing Company. 2000.

[28] Moore GE. The role of exercise prescription in chronic disease/ Br J Sports Med. 2004; 38: 5-7.

[29] Laskowski E. The effect of exercise in the treatment of obesity Mayo Clinic, Physical Medicine and Rehabilitation, Rochester, MN, USA. 13 July 2018.

[30] Booth FW, Roberts CK, Laye MJ. Lack of exercise is a major cause of chronic diseases. Compr Physiol. 2012; 2(2): 1143-1211.

[31] Friedenreich CM, Woolcott CG, McTiernan A, et al. Adiposity changes after a 1-year aerobic exercise intervention among postmenopausal women: a randomized controlled trial. Int J Obes. 2010; 35: 422-432.

[32] Aune D, Norat T, Leitzmann M, Tonstad S, Vatten LJ. Physical activity and the risk of type 2 diabetes: a systematic review and dose-response meta-analysis. Eur J Epidemiol. 2015; 30: 530-542.

[33] Hu G, Lindstrom J, Valle TT, et al. Physical activity, body mass index, and risk of type 2 diabetes in patients with normal or impaired glucose regulation. Arch Intern Med. 2004; 164: 892.

[34] George A. Kelley, Kristi S. Kelley. Effects of Exercise in the Treatment of Overweight and Obese Children and Adolescents: A Systematic Review of Meta-Analyses Hindawi Publishing Corporation Journal of Obesity. 2013, Article ID 783103, 10.

[35] World Health Organization. Assessing national capacity for the prevention and control of noncommunicable diseases. Geneva: WHO. 2012.

[36] World Cancer Research Fund/American Institute for Cancer Research. Food, nutrition, physical activity, and the prevention of cancer: a global perspective. Washington, DC: AICR. 2007.

[37] World Cancer Research Fund/American Institute for Cancer Research. Food, nutrition, physical activity and colorectal cancer. 2017.

[38] Keum N, Bao Y, Smith-Warner SA, Orav J, Wu K, Fuchs CS, Giovannucci EL. Association of physical activity by type and intensity with digestive system cancer risk. JAMA Oncol. 2016; 2: 1146-53.

[39] World Cancer Research Fund/American Institute for Cancer Research. Food, nutrition, physical activity and the prevention of breast cancer. 2010.

[40] Schmid D, Behrens G, Keimling M, Jochem C, Ricci C, Leitzmann M. A systematic review and meta-analysis of physical activity and endometrial cancer risk. Eur J Epidemiol. 2015; 30: 398-410.

[41] Moore SC, Lee IM, Weiderpass E, Campbell PT, Sampson JN, Kitahara CM, Keadle SK, Arem H, Berrington de Gonzalez A, Hartge P, Adami H-O, Blair CK, Borch KB, Boyd E, Check DP, Fournier A, Freedman ND, Gunter M, Johannson M, Khaw K-T, Linet MS, Orsini N, Park Y, Riboli E, Robien K, Schairer C, Sesso H, Spriggs M, Van Dusen R, Wolk A, Matthews CE, Patel AV. Association of leisure-time physical activity with risk of 26 types of cancer in 1.44 million adults. JAMA Intern Med. 2016; 176: 816-25.

[42] I-Min Lee, Paffenbarger RS Jr. The Role of Physical Activity in the Prevention of Coronary Artery Disease. In: Paul D Thompson, editor. Exercise and Sports Cardiology. 1st ed. New York: Mc Graw Hill. 2001; 384-400.

[43] Lee DC, Pate RR, Lavie CJ, Sui X, Church TS, Blair SN. Leisure-time running reduces all-cause and cardiovascular mortality risk. J Am Coll Cardiol. 2014; 64: 473-480.

[44] Smith SC Jr, Collins A, Ferrari R, et al. Our time: a call to save preventable death from cardiovascular disease (heart disease and stroke). Circulation. 2012; 126: 2770-2774.

[45] Carson KV, Chandratilleke MG, Picot J, Brinn MP, Esterman AJ, Smith BJ. Physical training for asthma. Cochrane Database Syst Rev. 2013; 9: CD001116.

[46] Nguyen HQ, Chu L, Amy Liu IL, et al. Associations between physical activity and 30-day readmission risk in chronic obstructive pulmonary disease. Ann Am Thorac Soc. 2014; 11: 695705.

[47] Renolleau-Courtois D, Lamouroux-Delay A, Delpierre S, et al. Home-based respiratory rehabilitation in adult patients with moderate or severe persistent asthma. J Asthma. 2014; 51: 552-558.

[48] Corbridge SJ and Nyenhuis SM. Promoting Physical Activity and Exercise in Patients with Asthma and Chronic Obstructive Pulmonary Disease. The journal for nurse practitioners. January 2017; 13(1): 41-46. 
[49] Burr JF, Davidson W, Shephard RJ, Eves N. Assessing risks for physical activity clearance and prescription. 2012; 58: 761-764.

[50] Vaes AW, Garcia-Aymerich J, Marott JL, et al. Changes in physical activity and all-cause mortality in COPD. Eur Respir J. 2014; 44: 1199-1209.

[51] Ferreira-Vieira TH, Bastos CP, Pereira GS, Moreira FA, Massensini AR. A role for the endocannabinoid system in exerciseinduced spatial memory enhancement in mice. Hippocampus. 2014; 24: 80-88.

[52] Fuss J, Steinle J, Bindila L, Auer MK, Kirchherr H, Lutz B, et al. A runner's high depends on cannabinoid receptors in mice. Proc. Natl. Acad. Sci. U.S.A. 2015; 112: 13105-13108.

[53] Mammen G, Faulkner G. (2013). Physical activity and the prevention of depression: a systematic review of prospective studies. Am. J. Prev. Med. 2013; 45: 650-657.

[54] De Moor MH, Beem AL, Stubbe JH, Boomsma DI, De Geus EJC. (2006). Regular exercise, anxiety, depression and personality: a populationbased study. Prev. Med. 2006; 42: 272-279.

[55] Hötting K, Schickert N, Kaiser J, Röder B, Schmidt-Kassow M. The effects of acute physical exercise on memory, peripheral bdnf, and cortisol in young adults. Neural Plast. 2016; 1-12.

[56] Mandolesi L, Gelfo F, Serra L, Montuori S, Polverino A, Curcio G, et al. Environmental factors promoting neural plasticity: insights from animal and human studies. Neural Plast. 2017; 1-10.

[57] Fernandes J, Arida RM, Gomez-Pinilla F. Physical exercise as an epigenetic modulator of brain plasticity and cognition. Neurosci. Biobehav. Rev. 2017; 80: 444-456.

[58] Chieffi S, Messina G, Villano I, Messina A, Valenzano A, Moscatelli F, et al. Neuroprotective effects of physical activity: evidence from human and animal studies. Front. Neurol. 2017; 8: 188.

[59] Niemann C, Godde B, Staudinger UM, Voelcker-Rehage C. Exercise-induced changes in basal ganglia volume and cognition in older adults. Neuroscience. 2014; 281: 146-163.

[60] Hollamby A, Davelaar EJ, Cadar D. Increased physical fitness is associated with higher executive functioning in people with dementia. Front. Public Heal. 2017; 5: 346.

[61] Pedrinolla A, Schena F, Venturelli M. Resilience to Alzheimer's disease: the role of physical activity. Curr. Alzheimer Res. 2017; 14: 545-552.

[62] Gureev AP, Shaforostova EA, Popov VN. Regulation of Mitochondrial Biogenesis as a Way for Active Longevity: Interaction Between the Nrf2 and PGC-1 $\alpha$ Signaling Pathways. Front Genet. 2019; 10: 435.

[63] Liang H, Ward WF. PGC-1alpha: a key regulator of energy metabolism. Adv Physiol Educ. 2006; 30 (4): $145-151$.

[64] Handschin C, Spiegelman BM. Peroxisome proliferator-activated receptor gamma coactivator 1 coactivators, energy homeostasis, and metabolism. Endocr Rev. 2006; 27: 728-735.

[65] Bonen A, Dohm GL, van Loon LJ. Lipid metabolism, exercise and insulin action. Essays Biochem. 2006; 42: 47-59.

[66] Lira VA, Benton CR, Yan Z, Bonen A. PGC-1alpha regulation by exercise training and its influences on muscle function and insulin sensitivity. Am J Physiol Endocrinol Metab. 2010; 299(2): E145-E161.

[67] Done AJ, Traustadóttir T. Nrf2 mediates redox adaptations to exercise. Redox Biol. 2016; 10: 191-199.

[68] Rothman SM, Griffioen KJ, Wan R, Mattson MP. Brain-derived neurotrophic factor as a regulator of systemic and brain energy metabolism and cardiovascular health. Ann. N.Y. Acad. Sci. 2012; 1264: 49-63.

[69] Cotman CW, Berchtold NC, Christie LA. Exercise builds brain health: key roles of growth factor cascades and inflammation. Trends Neurosci. 2007; 30: 464-472.

[70] Ivy AS, Rodriguez FG, Garcia C, Chen MJ, Russo-Neustadt AA. Noradrenergic and serotonergic blockade inhibits BDNF mRNA activation following exercise and antidepressant. Pharmacol. Biochem. Behav. 2003; 75, 81-88.

[71] Voss MW, et al. The influence of aerobic fitness on cerebral white matter integrity and cognitive function in older adults: results of a one-year exercise intervention. Hum. Brain Mapp. 2013; 34, 2972-2985. 